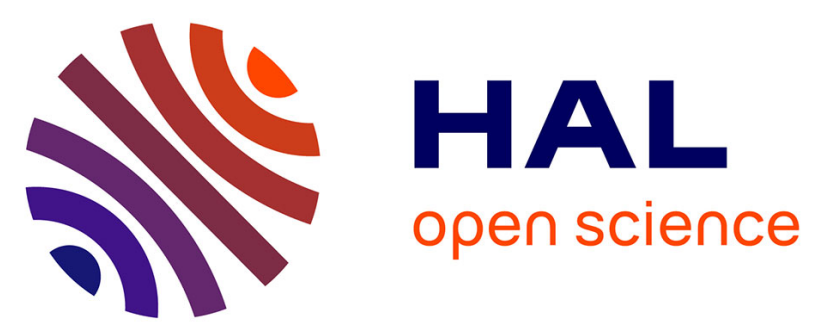

\title{
In situ formation of rare-earth-doped nanoparticles in a silica matrix from Molecular Dynamics simulations
}

\author{
Jérémy Turlier, Jorel Fourmont, Xavier Bidault, Wilfried Blanc, Stéphane
}

Chaussedent

\section{- To cite this version:}

Jérémy Turlier, Jorel Fourmont, Xavier Bidault, Wilfried Blanc, Stéphane Chaussedent. In situ formation of rare-earth-doped nanoparticles in a silica matrix from Molecular Dynamics simulations. Ceramics International, 2020, 46 (16), pp.26264-26272. 10.1016/j.ceramint.2020.03.293 . hal-02944807

\section{HAL Id: hal-02944807 \\ https://univ-angers.hal.science/hal-02944807}

Submitted on 12 Jan 2021

HAL is a multi-disciplinary open access archive for the deposit and dissemination of scientific research documents, whether they are published or not. The documents may come from teaching and research institutions in France or abroad, or from public or private research centers.
L'archive ouverte pluridisciplinaire HAL, est destinée au dépôt et à la diffusion de documents scientifiques de niveau recherche, publiés ou non, émanant des établissements d'enseignement et de recherche français ou étrangers, des laboratoires publics ou privés. 


\title{
Title
}

In situ formation of rare-earth-doped nanoparticles in a silica matrix from Molecular Dynamics simulations

\section{Authors}

Jérémy Turlier ${ }^{1}$, Jorel Fourmont ${ }^{1}$, Xavier Bidault ${ }^{1,2}$, Wilfried Blanc ${ }^{3}$ and Stéphane Chaussedent ${ }^{1, *}$

\section{Affiliations}

${ }^{1}$ Laboratoire de Photonique d'Angers (LPhiA), EA 4464, Université d'Angers, 49045 Angers, France

${ }^{2}$ University of Illinois at Chicago, Department of Civil and Material Engineering, Chicago, USA

${ }^{3}$ Université Côte d'Azur, CNRS, Institut de Physique de Nice (INPHYNI), UMR 7010, 06108 Nice, France

* Corresponding author: stephane.chaussedent@univ-angers.fr

\begin{abstract}
Developing new rare-earth-doped optical glasses with "enhanced" spectroscopic properties requires the elaboration of new glass compositions. To overcome some typical limitations of silica glass, a strategy consists in encapsulating rare-earth (RE) ions within oxide nanoparticles (NPs) through a phase separation mechanism. In this paper, Molecular Dynamics simulations were performed using an interatomic potential reproducing the phase separation within a $\mathrm{MgO}-\mathrm{SiO}_{2}$ binary melt to obtain RE-codoped glass models with $\mathrm{RE}=\mathrm{Eu}$ or Er. In these structures, we observed that Mg-rich regions, included into a silica-rich matrix and identified as NPs, are amorphous and exhibit a large range of sizes. We showed that such nanoparticles are the host of a depolymerization phenomenon of the $\mathrm{NPs}^{\prime} \mathrm{SiO}_{4}$ tetrahedral network leading to a release of nonbridging oxygen atoms. In the NPs, the $\mathrm{MgO}$ concentration increases and the doping RE ions are mainly located into the NPs where they are over-concentrated compared with the nominal doping concentration. However, the induced clustering effect is limited because of the non-bridging-oxygen-rich environment encountered in the NPs. This numerical analysis allows to give an insight on the chemical composition of the NPs, and especially on the local environment of the encapsulated rare-earth ions.
\end{abstract}




\section{Keywords}

Molecular Dynamics ; Nanoparticles ; MgO ; Silicate ; Rare-earth ; Glass.

\section{Main text}

\section{Introduction}

Rare-earth (RE)-doped silica-based glasses are materials of great importance for technological applications such as fiber lasers, optical amplifiers, sensors..., and have grown considerably in recent years. They combine luminescent properties of RE ions with the chemical, mechanical and financial advantages of the silica glass. However, the development of new applications using them as an amplifying material through the stimulated emission of the luminescent ions requires rethinking the nature and structure of these doped glasses to achieve "augmented" spectroscopic properties [1,2], which would not appear in a pure silica local environment. To develop such new silica-based glasses, a strategy consists in incorporating RE-doped oxide nanoparticles (NPs) in a silica glassy matrix [3]. The encapsulation of luminescent ions in NPs enables to practice engineering of the luminescent response of the material through the control of the structure and composition of the RE environment [4, 5]. To obtain RE-doped NPs in silica matrix, Blanc et al. [6] take advantage of the so-called phase separation phenomenon [7] occurring at high temperature in the $\mathrm{MgO}_{-} \mathrm{SiO}_{2}$ binary system during melt/quench sequences of glass fabrication. After quenching process, phase separation leads to a binary glass composed of two different phases: a Mg-rich Si-poor phase, identified as the NP, and a Si-rich Mg-poor phase, identified as the silica host matrix. Secondary Ion Mass Spectroscopy (SIMS) and Atom Probe Tomography (APT) measurements have confirmed the Mg-rich composition of such NPs wherein luminescent ions are mainly located [8, 9]. Vermillac et al. [10] have highlighted a broadening of the emission band of the ${ }^{4} \mathrm{I}_{13 / 2}$ level of $\mathrm{Er}^{3+}$ in erbium-doped silica-based fibers that were co-doped with magnesium or lanthanum. Recently, Blanc et al. [9] have shown, for the first time, a NP size-dependence of the chemical composition of amorphous Er-doped Mg-silicate NPs produced in situ in a silica glass.

However, detailed structural properties such as RE local environment, coordination numbers, oxygen species, are difficult to obtain from experiments because of the size of the NPs and of the low concentration of RE used for doping. Therefore, numerical simulations are very helpful to further investigate the structural properties at the nanoscale. 
The aim of this work is to discuss in detail the structural and compositional properties of RE-doped Mg-silicate NPs as well as the local environment encountered by RE ions. To this purpose, Molecular Dynamics (MD) simulations have been performed using an interatomic adaptive potential developed by Bidault et al. [11] that has allowed to reproduce the phase separation of the $\mathrm{xMgO}-(1-\mathrm{x}) \mathrm{SiO}_{2}$ binary glass. Through melt/quench protocol, we have elaborated three glasses with different chemical compositions: $0.10 \mathrm{MgO}-0.90 \mathrm{SiO}_{2}, 0.01 \mathrm{ErO}_{3 / 2}-0.10 \mathrm{MgO}-0.89 \mathrm{SiO}_{2}$, and $0.01 \mathrm{EuO}_{3 / 2}-0.10 \mathrm{MgO}-0.89 \mathrm{SiO}_{2}$. From these modeled structures, the RE-doped Mg-silicate NPs are identified and characterized in size, shape, and composition. The structure of magnesium and RE environments is analyzed in details, and we particularly focus on the effect of the Mg codoping on the RE local environment. The question of the RE clustering is finally discussed.

\section{Material and methods}

\subsection{Interatomic potential}

Since silica is a glass former of prime importance, a large variety of interatomic potentials has been designed to investigate its structural and dynamical properties [12-16]. Among them, pairwise potentials with partial charges have been extensively used, since they allow, for a reasonable calculation cost, to model glass samples containing up to several hundreds of thousands atoms during millions of timesteps. In this work, we adopt a modified version of the interatomic pairwise potential developed by Pedone et al. [12], which is known to accurately reproduce the structural properties of amorphous $\mathrm{SiO}_{2}$. Its functional form is a sum of a long-range Coulomb term, a short-range Morse function, and a repulsive contribution. Thus, the potential between particles $i$ and $j$ is given by:

$$
U\left(r_{i j}\right)=\frac{q_{i} q_{j}}{r_{i j}}+D_{i j}\left[\left\{1-e^{-a_{i j}\left(r_{i j}-r_{0}\right)}\right\}^{2}-1\right]+\frac{C_{i j}}{r_{i j}^{12}}
$$

where $q_{i}$ and $q_{j}$ are partial charges, $D_{i j}, C_{i j}, a_{i j}$ and $r_{0}$ are adjustable parameters and $r_{i j}$ is the interatomic distance. Short-range interactions were truncated at 5.5 A. The Coulomb part was evaluated using Wolf method [17] with a long-range cutoff set as $7.5 \AA$ and a damping parameter set as $0.30 \AA^{-1}$.

In a previous work, Bidault et al. [11] highlighted the inability of a fixed charge model to reproduce the phase separation phenomenon occurring in binary silicate glasses. The authors refined the Pedone potential in order to reproduce the phase diagram of the $\mathrm{MgO}-\mathrm{SiO}_{2}$ system, by taking into account the different ionicity of $\mathrm{Mg}-\mathrm{O}$ and $\mathrm{Si}-\mathrm{O}$ bonds, which is known to be crucial to model the phase separation 
phenomenon [18]. In order to respect the electroneutrality of the binary system and to explore the whole phase diagram by means of a unique set of parameters, each oxygen charge of the O-O repulsive interaction dynamically reacts to its own cationic environment. Details on the procedure can be found in Ref. [11]. These modifications allow to reproduce the separation of large phases in the $\mathrm{MgO}-\mathrm{SiO}_{2}$ binary system: $\mathrm{Mg}$-rich $\mathrm{Si}$ poor ones on one hand, and Si-rich Mg-poor ones on the other hand. Since phase separation phenomenon occurs in $\mathrm{REO}_{3 / 2}-\mathrm{SiO}_{2}$ systems (with $\mathrm{RE}=\mathrm{Eu}$ and $\mathrm{Er}$ ) [18, 19], it is also necessary to consider the ionicity of Er-O and Eu-O bonds. All potential parameters used in this study are listed in Table 1.

\section{[Tab 1 around here]}

\subsection{Simulation procedure}

MD simulations were performed to obtain three glass samples with a volume of approximately $200 \times 50 \times 200 \AA^{3}$ and molar compositions of $0.10 \mathrm{MgO}-0.90 \mathrm{SiO}_{2}(150336$ atoms: $5184 \mathrm{Mg}), 0.01 \mathrm{EuO}_{3 / 2}-$ $0.10 \mathrm{MgO}-0.89 \mathrm{SiO}_{2}$, and $0.01 \mathrm{ErO}_{3 / 2}-0.10 \mathrm{MgO}-0.89 \mathrm{SiO}_{2}(151824$ atoms: $5248 \mathrm{Mg}$, and $544 \mathrm{Eu}$ or Er). They were carried out by the LAMMPS (Large-scale Atomic/Molecular Massively Parallel Simulator) program [20] with periodic boundary conditions. The Velocity-Störmer-Verlet algorithm was used to solve Newton's equations of motion with a 1 fs timestep.

Glass sample elaboration was done at constant number of atoms, pressure and temperature using a Berendsen barostat and a Langevin thermostat. For each of the three glasses, the same numerical protocol was applied: in a first step, a silica glass was obtained by melting and equilibrating a cristobalite silica structure at $4000 \mathrm{~K}$ during $0.1 \mathrm{~ns}$. Then, the sample was cooled down to $300 \mathrm{~K}$ at a quench rate of $5 \times 10^{12} \mathrm{~K} . \mathrm{s}^{-}$

1. Secondly, $\mathrm{O}, \mathrm{Mg}$, and $\mathrm{RE}$ (Eu or Er) atoms were placed randomly in the silica matrix to obtain the desired chemical composition. Then, another melt/quench sequence was performed in order to obtain the final glass model: the system was melted and equilibrated at $4000 \mathrm{~K}$ during $0.1 \mathrm{~ns}$, and quenched at $5 \times 10^{11} \mathrm{~K} \cdot \mathrm{s}^{-1}$ from $4000 \mathrm{~K}$ to $2400 \mathrm{~K}$; then, long stages of $6.4 \mathrm{~ns}$ each were successively performed at $2400 \mathrm{~K}, 2300 \mathrm{~K}, 2200 \mathrm{~K}$, $2100 \mathrm{~K}, 2000 \mathrm{~K}$, and $1900 \mathrm{~K}$, a temperature range wherein the phase separation occurs [7]; at $1900 \mathrm{~K}$, which is below the glass transition temperature $\mathrm{T}_{\mathrm{g}}$, the system is almost fixed (for this quench rate, $\mathrm{T}_{\mathrm{g}}=2210 \mathrm{~K}$, $2150 \mathrm{~K}, 2160 \mathrm{~K}$ for $0.10 \mathrm{MgO}-0.90 \mathrm{SiO}_{2}$ glass, $0.01 \mathrm{ErO}_{3 / 2}-0.10 \mathrm{MgO}-0.89 \mathrm{SiO}_{2}$ glass, and $0.01 \mathrm{EuO}_{3 / 2}{ }^{-}$ $0.10 \mathrm{MgO}-0.89 \mathrm{SiO}_{2}$ glass, respectively). Finally, the system was quenched at $5 \times 10^{11} \mathrm{~K}^{-1}{ }^{-1}$ from $1900 \mathrm{~K}$ to $300 \mathrm{~K}$. All the results presented in this paper were derived from these three equilibrated structures at $300 \mathrm{~K}$ and atmospheric pressure. 


\section{Results and Discussion}

\subsection{Nanoparticles' characteristics}

MD visualizations were obtained using OVITO software [21]. In Fig. 1a, snapshots of the 0.10MgO$0.90 \mathrm{SiO}_{2}$ glass structure obtained by MD show the existence of two different kinds of region: Mg-rich Sipoor phases on one hand and Si-rich Mg-poor phases on the other hand. This observation of compositional heterogeneities is in agreement with experimental analysis using Secondary Ion Mass Spectroscopy (SIMS) and Atom Probe Tomography (APT) techniques [8, 9], as observed in Fig. 1b, where NPs seem to be amorphous and have a non-spherical shape. Figure 2 displays the Mg-Mg Radial Distribution Function (RDF) and Mg-Mg Cumulative Distribution Function (CDF) for the three glass models. We observe that the $\mathrm{Mg}-\mathrm{Mg} \mathrm{RDF}$ first peak is largely broadened around a mean distance of $3.0 \AA$, indicating that there is no crystalline arrangement in the $\mathrm{MgO}$ rich phases.

\section{[Fig $1 \& 2$ around here]}

Fig. 3 displays snapshots of the undoped and the RE-doped glass structures. Only Mg atoms are represented with a color code related to the size of the $\mathrm{Mg}$-rich phase in which they are located. $\mathrm{Two} \mathrm{Mg}$ atoms separated by less than $4.4 \AA$ (this $\mathrm{Mg}-\mathrm{Mg}$ cut-off distance corresponds to the position of the first minimum of the Mg-Mg RDF, see Fig. 2) are considered to belong to the same Mg-rich phase. We now identified these Mg-rich regions as nanoparticles (NPs). A visual analysis of snapshots indicates that NPs have a non-spherical shape and are inhomogeneously distributed in the silica matrix. They also exhibit a wide range of sizes: for the three glass models, about $10 \%$ of $\mathrm{Mg}$ atoms are isolated in silica, and about $60 \%$ are involved into NPs composed of $28 \mathrm{Mg}$ atoms and more. The largest NP observed among these three glass samples is composed of $525 \mathrm{Mg}$ atoms, with a length of about $100 \AA$.

\section{[Fig 3 around here]}

\section{[Tab 2 around here]}

Table 2 reports the NPs composition according to their size. NP composition is determined as following: an atom $\mathrm{R}(\mathrm{R}=\mathrm{Si}$, Eu or Er) is considered belonging to a NP if it is bounded to an oxygen atom which is itself bounded to a Mg atom of the NP. In practice, an atom R belongs to a NP if it is found at a distance shorter than the first minimum of R-Mg RDF from a Mg atom of the NP. For the three glass 
samples, we notice that the $\mathrm{MgO}$ concentration of a NP increases with its size. Whatever the NP size, rareearth ions are over-concentrated compared to their nominal concentration of $1 \%$. Only $12.5 \%$ of Eu ions ( $7.5 \%$ of Er ions) are isolated in the silica matrix. While the $\mathrm{EuO}_{3 / 2}$ concentration in the NPs seems to be almost constant whatever their size, the $\mathrm{ErO}_{3 / 2}$ concentration significantly increases in the largest NPs.

\subsection{Structure of magnesium environment}

$\mathrm{Mg}^{2+}$ cation is known to act as a network modifier in silicate melts, according to several models describing most of the relevant aspects which lead to glass formation [22, 23]. To appreciate the tetrahedral connectivity, it is commonly used to distinguish five $\mathrm{Q}^{n}$ silicon species according to the number $(n=0 \ldots 4)$ of bridging oxygen atoms per silicon tetrahedron. In such a way, a pure and perfect vitreous silica should exhibit $100 \%$ of $\mathrm{Q}^{4}$, meaning that all $\mathrm{Si}$ atoms are connected to four bridging oxygen (BO) [24]. Since the addition of $\mathrm{MgO}$ forms non-bridging oxygen (NBO), the $\mathrm{Q}^{n}$ distribution should become dependent on the $\mathrm{MgO}$ concentration. Table 3 reports $\mathrm{Q}^{n}$ distributions for $\mathrm{Si}$ atoms within the NPs of the $0.10 \mathrm{MgO}-0.90 \mathrm{SiO}_{2}$ glass, as a function of the NPs size. We can observe that as the NP size increases, the fraction of $\mathrm{Q}^{4}$ decreases, while the number of $\mathrm{Q}^{2}$ and $\mathrm{Q}^{3}$ units increases. As expected, the degree of depolymerization of the $\mathrm{SiO}_{2}$ network in the NP increases with their size, which is due to the fact that the $\mathrm{MgO}$ concentration also increases with the NPs size.

\section{[Tab 3 around here]}

We now report and discuss the local environment of $\mathrm{Mg}$ atoms and its effect on the depolymerization of the silica network in the $0.10 \mathrm{MgO}-0.90 \mathrm{SiO}_{2}$ glass model. Figure 4 displays the first peak of the Mg-O RDF as a function of the NP size in which $\mathrm{Mg}$ atoms are involved. We can observe a change in the shape and position of this peak. The average $\mathrm{Mg}-\mathrm{O}$ nearest neighbor distance and coordination number increase from $1.92 \AA\left(\mathrm{N}_{\mathrm{Mg}-\mathrm{O}}=5.6\right)$ for $\mathrm{Mg}$ in the silica matrix, to $2.04 \AA\left(\mathrm{N}_{\mathrm{Mg}-\mathrm{O}}=6.2\right)$ in the largest NPs. It is also interesting to note that for an isolated $\mathrm{Mg}$ atom in the silica matrix, the $\mathrm{Mg}-\mathrm{O} \mathrm{RDF}$ appears to be the result of two main contributions, indicating that two different oxygen species are encountered: oxygen atoms bonded to only one Si atom, which may be the closest to $\mathrm{Mg}$ (corresponding to the first peak), and oxygen atoms bonded to two $\mathrm{Si}$ atoms, which may be the farther from $\mathrm{Mg}$ (corresponding to the shoulder after the first peak). This assumption is analyzed and verified hereafter.

[Fig 4 around here] 
To investigate in more detail the Mg local environment, we use the terminology used by Afify and Mountjoy [25] to define the different oxygen species, as depicted on the right side of Fig. 5: a BO also bounded to one $\mathrm{Mg}$ atom is called $\mathrm{BO} *$; a $\mathrm{NBO}$ bounded to one $\mathrm{Mg}$ atom is denoted $\mathrm{NBO} *$, whereas a $\mathrm{NBO}$ bounded to two $\mathrm{Mg}$ atoms is denoted NBO**; finally, a Non-Network Oxygen (NNO) is an oxygen atom not bounded to any $\mathrm{Si}$, but only to $\mathrm{Mg}$ atoms. The left side of Fig. 5 displays the Mg-O RDF and its contributions due to the previously defined oxygen species in the $0.10 \mathrm{MgO}-0.90 \mathrm{SiO}_{2}$ glass model. We observe that the first maximum position is different for each contribution of the overall $\mathrm{MgO}$ RDF. It is located at around $1.90 \AA$, $2.05 \AA$, and $2.25 \AA$, for $\mathrm{Mg}-\mathrm{NBO}^{*}, \mathrm{Mg}-\mathrm{NBO}^{* *}$, and $\mathrm{Mg}-\mathrm{BO} *$, respectively. The $\mathrm{Mg}-\mathrm{BO} *$ interatomic distance is longer than the $\mathrm{Mg}-\mathrm{NBO}$ ones, because a $\mathrm{BO} *$ is strongly bounded to two $\mathrm{Si}$ atoms. In the same way, $\mathrm{Mg}-\mathrm{NBO}^{* *}$ distance is longer than the $\mathrm{Mg}-\mathrm{NBO}^{*}$ one, because a $\mathrm{NBO} * *$ is constrained to be bounded to another $\mathrm{Mg}$.

\section{[Fig 5 around here]}

Table 4 reports, for the same glass model, detailed oxygen coordination number of $\mathrm{Mg}$ as a function of the size of the NP in which it is located. The oxygen coordination number of $\mathrm{Mg}$ is provided by the area measured under the first peak of the RDF, using a cut-off distance of $2.9 \AA$ (which is the position of the RDF first minimum). In this glass model, the average oxygen coordination number of $\mathrm{Mg}$ is found to be 6.0. But results reported in Table 4 show that this coordination number depends on the NP size in which Mg atoms are considered, increasing from 5.6 when isolated in the silica matrix to 6.2 in the largest NPs. These modeled coordination numbers are in agreement with experimental values obtained by ${ }^{25} \mathrm{Mg} 3 \mathrm{QMAS}$ NMR [26] for an enstatite glass and by ${ }^{25} \mathrm{Mg}$ NMR spectroscopy [27] for $\mathrm{xMgO}-(1-\mathrm{x}) \mathrm{SiO}_{2}$ glasses where $0.50<\mathrm{x}<$ 0.67. These experimental results support the idea of a distorted octahedral environment for $\mathrm{Mg}$. In our modeled structures, it is found that with the increase of the NPs size, the coordination of $\mathrm{Mg}$ with $\mathrm{BO}^{*}$ and $\mathrm{NBO}^{*}$ decreases, and consequently the oxygen-rich environment found in the largest NPs is mostly due to the presence of $\mathrm{NBO}^{* *}$ and NNO. Table 4 also reports the distribution of sites occupied by $\mathrm{Mg}$ atoms according to the number of coordinated oxygen atoms and as a function of NPs size. Isolated in the silica matrix, Mg atoms are mainly surrounded by 5 and 6 oxygen atoms. When the NP size increases, these 5 - and 6-coordinated sites are less and less numerous, in favor of a majority of 6- and 7-coordinated sites for Mg in the largest NPs. Not reported here, the same analysis has been performed for the two RE-codoped glasses, and the same results on the $\mathrm{Mg}$ environment have been obtained. According to these results, the concentration in $\mathrm{MgO}$ and the average oxygen coordination of $\mathrm{Mg}$ are found to be nanoparticle size- 
dependent. The Mg-O coordination number is mostly due to the presence of non-bridging-oxygen, which is in good agreement with the network modifier role of $\mathrm{Mg}^{2+}$ cation.

[Tab 4 around here]

\subsection{Structure of rare-earth environment}

From the two glass models of $0.01 \mathrm{ErO}_{3 / 2}-0.10 \mathrm{MgO}-0.89 \mathrm{SiO}_{2}$ and $0.01 \mathrm{EuO}_{3 / 2}-0.10 \mathrm{MgO}-0.89 \mathrm{SiO}_{2}$ composition, the structure of the rare-earth ion's environment has been analyzed in detail. Fig. 6 displays the RDF and CDF for the RE-Mg and RE-Si pairs (RE = Eu and Er). Eu-Mg and Er-Mg RDFs presents an intense first peak but also a well-defined second peak meaning that $\mathrm{Mg}$ atoms are also present in the second cationic coordination sphere of the rare-earth ions. Considering the CDF curves at a cut-off radius corresponding to the RDF first minimum (4.7 $\AA$ for Eu-Mg, $4.3 \AA$ for Eu-Si, $4.6 \AA$ for Er-Mg and $4.1 \AA$ for $\mathrm{Er}-\mathrm{Si}$ ), one can deduce that the first cationic coordination sphere of Eu is on average composed of $2.3 \mathrm{Mg}$ and 7.4 Si, while Er is surrounded on average by 3.2 Mg and 6.8 Si. Since it has been previously seen that NPs are Mg-rich environments, it can be concluded that RE ions are mainly located in the NPs. Moreover, considering the differences between $\mathrm{Eu}$ and $\mathrm{Er}$, one can note that the environment of Er is richer in $\mathrm{Mg}$ than the one of Eu. Therefore, since the highest $\mathrm{MgO}$ concentration is found in largest NPs, it is expected to find a large fraction of $\mathrm{Er}^{3+}$ ions located in largest NPs. Actually, more than $40 \%$ of Er ions, against less than $25 \%$ of Eu ions, are found to be located in the largest NPs (composed of $126 \mathrm{Mg}$ and more). This is in agreement with the previous analysis on the NP composition, where it has been shown that the largest NPs are composed of $3.3 \%$ of $\mathrm{ErO}_{3 / 2}$ against $2.3 \%$ of $\mathrm{EuO}_{3 / 2}$ according to the rare-earth doping. The origin of this difference is discussed hereafter in the paper.

\section{[Fig 6 around here]}

In order to study the oxygen coordination of the rare-earth ions and especially to understand the effect of the $\mathrm{Mg}$ codoping, two glass models of composition $0.01 \mathrm{EuO}_{3 / 2}-0.99 \mathrm{SiO}_{2}$ and $0.01 \mathrm{ErO}_{3 / 2}-0.99 \mathrm{SiO}_{2}$ have been produced for comparison. Fig. 7 displays the RDF and CDF for the Eu-O and Er-O pairs. It can be observed that $\mathrm{Eu}-\mathrm{O}$ and $\mathrm{Er}-\mathrm{O}$ interatomic distances are shifted to larger distances with the addition of $\mathrm{Mg}$, which is the consequence of a change in the nature of the RE ions close environment. Using cut-off distances corresponding to the RDFs first minima (3.0 $\AA$ for Eu-O and $2.9 \AA$ for Er-O), the CDF curves indicate oxygen coordination numbers increasing from 6.07 to 6.61 for $\mathrm{Eu}$, and from 5.92 to 6.49 for Er. It means that for both RE ions, Mg codoping involves a significant increase of their oxygen coordination numbers. 


\section{[Fig 7 around here]}

In order to understand and compare the structuration of the RE first coordination sphere, statistics are reported in Fig. 8. As a function of the NPs size, oxygen coordination numbers of Eu and Er are discriminated according to their occurrence and their oxygen species composition (Fig. 8a). As it has been observed for Mg, these data clearly show that oxygen coordination of RE increases with the NPs size in which they are embedded. Within NPs, RE ions encountered the NBO-rich environment induced by the depolymerization of silica, and become mainly surrounded by NBO**. The largest NPs being the richest in $\mathrm{Mg}$ and NBO**, RE embedded in large NPs are coordinated with a higher number of oxygen atoms and especially of NBO**. Discriminating the RE sites according to their oxygen coordination number, Fig. 8b shows that the increase of coordination number with the NP size is essentially due to an increase of the proportion of 7- and 8-coordinated sites to the detriment of the 5- and 6-coordinated sites. One can also notice that, whatever the NP size in which RE ions are embedded, 6-coordinated sites are more frequent for Er than for Eu. Likewise, it has been previously shown that non-isolated Mg atoms were mostly coordinated by 6 oxygen atoms. It is also known that a $\mathrm{Mg}^{2+}$ ion occupying a 6-coordinated oxygen site can be substituted more easily by an $\mathrm{Er}^{3+}$ ion than by $\mathrm{a} \mathrm{Eu}^{3+}$ ion [28]. This observation is supported by considerations on ionic radii [29, 30]: $\mathrm{Er}^{3+}$ ionic radius, ranging from $0.89 \AA$ (VI) to $0.945 \AA$ (VII), is shorter than the one of $\mathrm{Eu}^{3+}$ $(0.947 \AA(\mathrm{VI})-1.01 \AA(\mathrm{VII}))$, and consequently closer to the one of $\mathrm{Mg}^{2+}(0.72 \AA)$. Reminding that the largest NPs are composed of $3.3 \%$ of $\mathrm{ErO}_{3 / 2}$ against $2.3 \%$ of $\mathrm{EuO}_{3 / 2}$ for the same nominal concentration, a stronger affinity of $\mathrm{Er}^{3+}$ ions for 6-coordinated sites, which are prevalent in most of NPs, may explain the better encapsulation of erbium compared with europium. In addition, these statistics are in good agreement with the "crystal-chemistry" model proposed by Wang et al. [31], where the ratio $\mathrm{r}_{\mathrm{RE}^{3+}} / \mathrm{r}_{\mathrm{O}}{ }^{2-}<0.732$ indicates that RE should be six-coordinated by oxygen (or seven-coordinated at very high rare-earth concentration) and the smaller RE ionic radius provides higher sites regularity.

\section{[Fig 8 around here]}

\subsection{Rare-earth clustering}

Because RE are over-concentrated in NPs, the question of the clustering has to be addressed. Indeed, it is well known that RE clustering occurs in silica matrix for concentrations beyond some hundreds of ppm $[32,33]$. Thus, we can here focus on the RE clustering within NPs. To study the degree of RE clustering, RE ions are categorized according to the size of the cluster they form: two RE ions are considered to belong to a 
same cluster if they are separated by less than $5.0 \AA$, which is the distance corresponding to the position of the first minimum of the Er-Er and Eu-Eu RDF curves. In such a way, isolated RE ions are called 1 RE, RE ions forming a pair are denoted $2 \mathrm{RE}$, and 3+ RE indicates RE ions within clusters composed of three or more RE ions. Statistics are reported in Table 5 for the two codoped glass models and compared with doped glass models (without $\mathrm{Mg}$ ). At first glance, the $\mathrm{Mg}$-codoping seems to induce an increase of the RE clustering trend. However, one has to keep in mind that Mg-codoping induces Mg-rich phases, i.e. the socalled NPs, where local RE concentration is much more than the nominal concentration of $1 \%$. Therefore, since the RE clustering is known to be favored by an increase of the RE concentration [25], it is expected to observe a global increase of the RE clustering when the RE are locally found over-concentrated in NPs. But the addressed question is: "Does the clustering degree remain in proportion with the RE concentration in the NPs?".

[Tab 5 around here]

\section{[Tab 9 around here]}

To answer this question, statistics on the RE clustering as a function of the NPs size have been computed and are reported in Fig. 9. For the sake of comparison, doped glass structures without $\mathrm{Mg}$ have been simulated with a RE concentration equivalent to the one found in the largest NPs of the codoped structures. Firstly, we observe that the fraction of isolated RE ions tends to decrease with the increase of the NPs size. Consequently, a larger fraction of RE ions are found to form cluster in the largest NPs. This is in agreement with the fact that RE concentration is more important in the largest NP than in the smaller ones. For instance, Er concentration reaches 3.3\% into the largest NPs (composed of $126 \mathrm{Mg}$ and more) wherein Er ions are $51.7 \%$ isolated and $22.1 \%$ form clusters of three and more RE. Comparing these data with those obtained from glass models of $0.023 \mathrm{EuO}_{3 / 2}-0.977 \mathrm{SiO}_{2}$ and $0.033 \mathrm{ErO}_{3 / 2}-0.967 \mathrm{SiO}_{2}$ compositions, one can observe that the clustering trend is significantly restrained. Indeed, for a same $\mathrm{ErO}_{3 / 2}$ concentration of $3.3 \%$, $51.7 \%$ of the Er ions remain isolated in the largest NPs whereas only $44.8 \%$ are isolated in the structure without Mg. Likewise, clusters of 3 or more RE ions are less prevalent in the large NPs than in the structure without Mg. Moreover, the same trend is observed for Eu and Er. In order to visualize this effect, Fig. 10 displays snapshots of the $0.033 \mathrm{ErO}_{3 / 2}-0.967 \mathrm{SiO}_{2}$ and $0.01 \mathrm{ErO}_{3 / 2}-0.10 \mathrm{MgO}-0.89 \mathrm{SiO}_{2}$ glass models where only Er ions are represented with a color code depending on the size of the cluster they form. For the sake of comparison, only Er ions involved in the largest NPs are represented in the codoped structure. From these 
snapshots and data of Fig. 9, we can assert that the presence of Mg-silicate NPs significantly prevents the formation of large RE clusters, which can be interpreted as a limiting clustering effect due to the oxygen enrichment of the local environment of RE ions embedded in the NPs.

\section{Conclusions}

Using MD simulations of RE-doped and RE-Mg-codoped silica glasses, it was found that a phase separation mechanism leads to the formation of $\mathrm{Mg}$-rich phases in which the RE ions are mostly embedded. Such heterogeneities, also observed experimentally by APT, can be considered as amorphous NPs of various sizes. This study has pointed out that the chemical composition of these NPs depends on their size, with Mg and RE concentrations increasing with the NP size. A detailed analysis of the NP structure and composition has revealed that the largest NP are over-concentrated in RE while the expected clustering trend is however limited. It was also observed that Er ions are encapsulated in a larger amount than Eu ions. The oxygen-rich environment found in the largest NPs is mostly due to the presence of non-bridging oxygen atoms brought by the Mg-silicate phase. It explains RE over-concentration in the largest NPs since in such NBO-rich environments the luminescent ions can satisfy higher oxygen coordination numbers. Due to ionic radius considerations, Er ions can substitute $\mathrm{Mg}$ ions more easily than Eu ions, explaining therefore a better encapsulation of Er ions in the NPs. Moreover, the clustering trend is limited because RE ions have less need to aggregate themselves to share $\mathrm{NBO}$ in the $\mathrm{Mg}$-silicate phase.

These results fully contribute to a better understanding of the size-dependent composition of NPs formed in situ in a silica matrix. With the aim of tailoring spectroscopic properties of luminescent ions in nanocomposite glasses, the ability to control their close environment through the size and composition of nanoparticles can make this study a relevant guide for the development of future materials. Works are in progress to deduce spectroscopic characteristics, through crystal field parameters calculation, from the different sites occupied by the luminescent ions in these nanostructured glass models.

\section{Declarations of interest}

None.

\section{Acknowledgements}


This study was funded by Université d'Angers and Agence Nationale de la Recherche (ANR-14-CE07-001603, Nice-Dream and ANR-17-CE08-0002, NanoSlim).

\section{References}

[1] D. Richardson, J. Nilsson, W. Clarkson, High power fiber lasers: current status and future perspectives, JOSA B 27 (2010) B63-B92. https://doi.org/10.1364/JOSAB.27.000B63.

[2] J. Ballato, H. Ebendorff-Heidepriem, J. Zhao, L. Petit, J. Troles, Glass and process development for the next generation of optical fibers: A review, Fibers 5 (2017) 11. https://doi.org/10.3390/fib5010011.

[3] A. Veber, Z. Lu, M. Vermillac, F. Pigeonneau, W. Blanc, L. Petit, Nano-Structured Optical Fibers Made of Glass-Ceramics, and Phase Separated and Metallic Particle-Containing Glasses, Fibers 7 (12), 105 (2019). https://doi.org/10.3390/fib7120105.

[4] B. N. Samson, P. A. Tick, N. F. Borrelli, Efficient neodymium-doped glass-ceramic fiber laser and amplifier, Opt. Lett. 26 (2001) 145-147. https://doi.org/10.1364/OL.26.000145.

[5] J. Thomas, M. Myara, L. Troussellier, E. Burov, A. Pastouret, D. Boivin, G. Mélin, O. Gilard, M. Sotom, P. Signoret, Radiation-resistant erbium-doped-nanoparticles optical fiber for space applications, Opt. Express 20 (2012) 2435-2444. https://doi.org/10.1364/OE.20.002435.

[6] W. Blanc, V. Mauroy, L. Nguyen, S. N. B. Bhaktha, P. Sebbah, B. Pal, B. Dussardier, Fabrication of Rare Earth-doped Transparent Glass Ceramic Optical Fibers by Modified Chemical Vapor Deposition, J. Am. Soc. 94 (2011) 2315-2318. https://doi.org/10.1111/j.1551-2916.2011.04672.x.

[7] V. B. M. Hageman, H. A. J. Oonk, Liquid immiscibility in the $\mathrm{SiO}_{2}+\mathrm{MgO}, \mathrm{SiO}_{2}+\mathrm{SnO}, \mathrm{SiO}_{2}+\mathrm{La}_{2} \mathrm{O}_{3}$, and $\mathrm{SiO}_{2}+\mathrm{Y}_{2} \mathrm{O}_{3}$ systems, Phys. Chem. Glasses 27 (1986) 194-198.

[8] W. Blanc, C. Guillermier, B. Dussardier, Composition of nanoparticles in optical fibers by Secondary Ion Mass Spectroscopy, Opt. Mater. Express 2 (2012) 1504-1510. https://doi.org/10.1364/OME.2.001504.

[9] W. Blanc, I. Martin, H. François-Saint-Cyr, X. Bidault, S. Chaussedent, C. Hombourger, S. Lacomme, P. Le Coustumer, D. R. Neuville, D. J. Larson, T. J. Prosa, C. Guillermier, Compositional Changes at the Early Stages of Nanoparticles Growth in Glasses, J. Phys. Chem. C 123 (2019) 29008-29014. https://doi.org/10.1021/acs.jpcc.9b08577. 
[10] M. Vermillac, J. F. Lupi, S. Trzesien, M. Ude, W. Blanc, On the Enlargement of the Emission Spectra from the ${ }^{4} \mathrm{I}_{13 / 2}$ Level of $\mathrm{Er}^{3+}$ in Silica-Based Optical Fibers through Lanthanum or Magnesium Co-Doping, Ceramics 1 (2018) 364-374. https://doi.org/10.3390/ceramics1020029.

[11] X. Bidault, S. Chaussedent, W. Blanc, A simple transferable adaptive potential to study phase separation in large-scale xMgO-(1-x) $\mathrm{SiO}_{2}$ binary glasses, J. Chem. Phys. 143 (2015) 154501. https://doi.org/10.1063/1.4932984.

[12] A. Pedone, G. Malavasi, M. Cristina Menziani A. N. Cormack, U. Segre, New Self-Consistent Empirical Interatomic Potential Model for Oxides, Silicates, and Silica-Based Glasses, J. Phys. Chem. 110 (2006) 11780-11795. https://doi.org/10.1021/jp0611018.

[13] B. P. Feuston, S. H. Garofalini, Empirical three-body potential for vitreous silica, J. Chem. Phys. 89 (1988) 5818-5824. https://doi.org/10.1063/1.455531.

[14] B. W. H. van Beest, G. J. Kramer, R. A. van Santen, Force fields for silicas and aluminophosphates based on ab initio calculations, Phys. Rev. Lett. 64 (1990) 1955-1958. https://doi.org/10.1103/PhysRevLett.64.1955.

[15] A. N. Cormack, J. Du, T. R. Zeitler, Sodium ion migration mechanisms in silicate glasses probes by molecular dynamics simulations, J. Non-Cryst. Solids 323 (2003) 147-154. https://doi.org/10.1016/S00223093(03)00280-1.

[16] N. D. Afify, G. Mountjoy, R. Haworth, Selecting reliable interatomic potentials for classical molecular dynamics simulations of glasses: The case of amorphous $\mathrm{SiO}_{2}$, Comput. Mater. Sci. 128 (2017) 75-80. https://doi.org/10.1016/j.commatsci.2016.10.046.

[17] D. Wolf, P. Keblinski, S. R. Phillpot, J. Eggebrecht, Exact method for the simulation of Coulombic systems by spherically truncated, pairwise r-1 summation, J. Chem. Phys. 110 (1999) 8254-8282. https://doi.org/10.1063/1.478738.

[18] P. Hudon, D. R. Baker, The nature of phase separation in binary oxide melts and glasses. I. Silicate systems, J. Non-Cryst. Solids 303 (2002) 299-345. https://doi.org/10.1016/S0022-3093(02)01043-8. 
[19] N. A. Toporov, F. Ya.; Galakhov, S. F. Konovalova, Silicates of the rare earth elements communication 5. Phase diagrams of the $\mathrm{Dy}_{2} \mathrm{O}_{3}-\mathrm{SiO}_{2}$ and $\mathrm{Er}_{2} \mathrm{O}_{3}-\mathrm{SiO}_{2}$ systems, Bull. Acad. Sci. USSR Div. Chem. Sci. 10 (1961) 1271-1277. https://doi.org/10.1007/BF00910094.

[20] S. Plimpton, Fast Parallel Algorithms for Short-Range Molecular Dynamics, J. Comp. Phys. 117 (1995) 1-19. https://doi.org/10.1006/jcph.1995.1039.

[21] A. Stukowski, Visualization and analysis of atomistic simulation data with OVITO - the Open Visualization Tool, Modelling Simul. Mater. Sci. Eng. 18 (2010) 015012. https://doi.org/10.1088/09650393/18/1/015012.

[22] K. H. Sun, Fundamental condition of glass formation, J. Am. Ceram. Soc. 30 (1947) 277-281. https://doi.org/10.1111/j.1151-2916.1947.tb19654.x.

[23] A. K. Varshneya, Fundamentals of Inorganic Glasses, first ed., Academic Press, 2013, pp. $27-39$.

[24] R. L. Mozzi, B. E. Warren, The structure of vitreous silica, J. Appl. Cryst. 2 (1969) 164-172. https://doi.org/10.1107/S0021889869006868.

[25] N. D. Afify, G. Mountjoy, Molecular-dynamics modeling of $\mathrm{Eu}^{3+}$-ion clustering in $\mathrm{SiO}_{2}$ glass, Phys. Rev. B 79 (2009) 024202. https://doi.org/10.1103/PhysRevB.79.024202.

[26] K. Shimoda, Y. Tobu, M. Hatakeyama, T. Nemoto, K. Saito, Structural investigation of Mg local environments in silicate glasses by ultra-high field ${ }^{25} \mathrm{Mg}$ 3QMAS NMR spectroscopy, Am. Mineral. 92 (2007) 695-698. https://doi.org/10.2138/am.2007.2535.

[27] S. Sen, H. Maekawa, G. N. Papatheodorou, Short-Range Structure of Invert Glasses along the PseudoBinary Join $\mathrm{MgSiO}_{3}-\mathrm{Mg}_{2} \mathrm{SiO}_{4}$ : Results from ${ }^{29} \mathrm{Si}$ and ${ }^{25} \mathrm{Mg}$ MAS NMR Spectroscopy, J. Phys. Chem. B 113 (2009) 15243-15248. https://doi.org/10.1021/jp9079603.

[28] R. Y. S. Zampiva, L. H. Acauan, J. Venturini, J. A. M. Garcia, D. S. da Silva, Z. Han, L. R. P. Kassab, N. U. Wetter, A. Agarwal, A. K. Alves, C. P. Bergmann, Tunable green/red luminescence by infrared upconversion in biocompatible forsterite nanoparticles with high erbium doping uptake, Opt. Mater. 76 (2018) 407-415. https://doi.org/10.1016/j.optmat.2018.01.004.

[29] R. D. Shannon, Revised effective ionic radii and systematic studies of interatomic distances in halides and chalcogenides, Acta Cryst. A32 (1976) 751-767. https://doi.org/10.1107/S0567739476001551. 
[30] R. D. Shannon, C. T. Prewitt, Effective ionic radii in oxides and fluorides, Acta Cryst. B25 (1969) 925946. https://doi.org/10.1107/S0567740869003220.

[31] J. Wang, W. S. Brocklesby, J. R. Lincoln, J. E. Townsend, D. N. Payne, Local structures of rare-earth ions in glasses: the "crystal-chemistry” approach, J. Non-Cryst. Solids 163 (1993) 261-267. https://doi.org/10.1016/0022-3093(93)91303-K.

[32] K. Arai, H. Namikawa, K. Kumata, T. Honda, Aluminum or phosphorus co-doping effects on the fluorescence and structural properties of neodymium-doped silica glass, J. Appl. Phys. 59 (1986) 3430-3436. https://doi.org/10.1063/1.336810.

[33] F. Auzel, P. Goldner, Towards rare-earth clustering control in doped glass, Opt. Mater. 16 (2001) 93103. https://doi.org/10.1016/S0925-3467(00)00064-1.

\section{Figure Captions}

Fig. 1. (a) Snapshots of the $0.10 \mathrm{MgO}-0.90 \mathrm{SiO}_{2}$ glass structure obtained by MD (oxygen atoms are not represented for the sake of clarity). (b) Comparison with APT analysis (extract from [9]), where Mg atoms are in magenta and silicon atoms are in blue.

Fig. 2. $\mathrm{Mg}-\mathrm{Mg} \mathrm{RDF}$ and $\mathrm{Mg}-\mathrm{Mg} \mathrm{CDF}$ in the three glass models.

Fig. 3. Snapshots showing: (a) $0.10 \mathrm{MgO}-0.90 \mathrm{SiO}_{2}$ glass model, (b) $0.01 \mathrm{ErO}_{3 / 2}-0.10 \mathrm{MgO}-0.89 \mathrm{SiO}_{2}$ glass model, and (c) $0.01 \mathrm{EuO}_{3 / 2}-0.10 \mathrm{MgO}-0.89 \mathrm{SiO}_{2}$ glass model. Only $\mathrm{Mg}$ atoms are represented with a color code related to the size of the nanoparticle ( $\mathrm{Si}, \mathrm{O}$ and $\mathrm{RE}$ atoms are not represented for the sake of clarity). 
Fig. 4. $\mathrm{Mg}-\mathrm{O} \mathrm{RDF}$ and $\mathrm{CDF}$ as a function of $\mathrm{NP}$ size (number of $\mathrm{Mg}$ atoms) in the $0.10 \mathrm{MgO}-0.90 \mathrm{SiO}_{2} \mathrm{glass}$ model.

Fig. 5. Different oxygen species contributions to the $\mathrm{Mg}-\mathrm{O} \mathrm{RDF}$ in the $0.10 \mathrm{MgO}-0.90 \mathrm{SiO}_{2}$ glass model, on the left side, and schematic representation of the different oxygen species (red, grey and green spheres represent oxygen, silicon and magnesium atoms, respectively), on the right side.

Fig. 6. $\mathrm{RE}-\mathrm{Mg}$ and $\mathrm{RE}-\mathrm{Si} \mathrm{RDF}$ and $\mathrm{CDF}(\mathrm{RE}=\mathrm{Eu}$ and $\mathrm{Er})$ in the two codoped-glass models.

Fig. 7. Eu-O and Er-O RDF and CDF with and without Mg-codoping.

Fig. 8. Details of RE-O coordination numbers as a function of the NP size in the $0.01 \mathrm{REO}_{3 / 2}-0.10 \mathrm{MgO}-$ $0.89 \mathrm{SiO}_{2}$ glass model $(\mathrm{Eu} / E r$-O cut-off $=3.0 / 2.9 \AA)$ : (a) distribution according to oxygen species and (b) distribution according to coordinated sites.

Fig. 9. (a) RE clustering in the $0.01 \mathrm{REO}_{3 / 2}-0.10 \mathrm{MgO}-0.89 \mathrm{SiO}_{2}$ glass model as a function of the NP size. (b) Comparison between the RE clustering found in the largest NPs (126 Mg and more) and the one occurring in a doped glass with a RE concentration equivalent to the one found in the largest NPs of the codoped structures.

Fig. 10. Snapshots of (a) all Er ions in the $0.033 \mathrm{ErO}_{3 / 2}-0.967 \mathrm{SiO}_{2}$ glass model, and (b) of Er ions belonging to the largest NPs $\left(126 \mathrm{Mg}\right.$ and more) in the $0.01 \mathrm{ErO}_{3 / 2}-0.10 \mathrm{MgO}-0.89 \mathrm{SiO}_{2}$ glass model. RE are represented with a color code depending on the size of the cluster they form. Cyan segments represent Si-O bonds and magenta segments represent $\mathrm{Mg}-\mathrm{O}$ bonds in the NPs.

\section{Tables}

\section{Table 1}

Potential parameters for MD modelling of $y \mathrm{REO}_{3 / 2}-\mathrm{xMgO}-(1-\mathrm{x}-\mathrm{y}) \mathrm{SiO}_{2}$ structures. Values given in exponent of ion type are partial charges. q and q': each oxygen partial charge depends on its own cationic environment.

Table 2

Nanoparticles composition as a function of their size.

Table 3

Details of $\mathrm{Q}^{\mathrm{n}}$ distributions of $\mathrm{Si}$ atoms within the NPs of the $0.10 \mathrm{MgO}-0.90 \mathrm{SiO}_{2}$ glass model.

\section{Table 4}

$\mathrm{Mg}-\mathrm{O}$ nearest neighbor distances $\mathrm{r}, \mathrm{Mg}-\mathrm{O}$ coordination numbers $\mathrm{N}$ and their distribution in $0.10 \mathrm{MgO}$ $0.90 \mathrm{SiO}_{2}$ glass model as a function of the NP size $(\mathrm{Mg}-\mathrm{O}$ cut-off $=2.9 \AA)$.

Table 5

Global statistics on the RE clustering for the codoped and doped glass models. 
Table 1.

\begin{tabular}{lcccc}
\hline & $\mathrm{D}_{\mathrm{ij}}(\mathrm{eV})$ & $\mathrm{a}_{\mathrm{ij}}\left(\AA^{-1}\right)$ & $\mathrm{r}_{0}(\AA)$ & $\mathrm{C}_{\mathrm{ij}}\left(\mathrm{eV} . \AA^{12}\right)$ \\
\hline $\mathrm{Si}^{2.4}-\mathrm{Si}^{2.4}$ & - & - & - & - \\
$\mathrm{Si}^{2.4}-\mathrm{O}^{-1.2}$ & 0.340554 & 2.006700 & 2.100000 & 1.0 \\
$\mathrm{Mg}^{1.33}-\mathrm{Mg}^{1.33}$ & - & - & - & - \\
$\mathrm{Mg}^{1.33}-\mathrm{Si}^{2.4}$ & - & - & - & - \\
$\mathrm{Mg}^{1.33}-\mathrm{O}^{-1.33}$ & 0.209290 & 1.376871 & 2.733041 & 1.0 \\
$\mathrm{RE}^{2.00}-\mathrm{RE}^{2.00}$ & - & - & - & - \\
$\mathrm{RE}^{2.00}-\mathrm{Si}^{2.4}$ & - & - & - & - \\
$\mathrm{Eu}^{2.00}-\mathrm{O}^{-1.33}$ & 0.000373 & 2.478247 & 3.770304 & 1.0 \\
$\mathrm{Er}^{2.00}-\mathrm{O}^{-1.33}$ & 0.000811 & 2.880949 & 3.344240 & 1.0 \\
$\mathrm{O}^{\mathrm{q}}-\mathrm{O}^{\mathrm{q}}$ & 0.042395 & 1.379316 & 3.618701 & 22.0 \\
\hline
\end{tabular}


Table 2.

\begin{tabular}{c|c|ccc}
\hline \multirow{2}{*}{$\begin{array}{c}\text { NP size } \\
\text { (number of } \\
\text { Mg atoms) }\end{array}$} & $0.10 \mathrm{MgO}-0.90 \mathrm{SiO}_{2}$ & \multicolumn{3}{|c}{$\begin{array}{c}0.01 \mathrm{REO}_{3 / 2}-0.10 \mathrm{MgO}-0.89 \mathrm{SiO}_{2} \\
\mathrm{RE}=\mathrm{Eu}^{3+} / \mathrm{Er}^{3+}\end{array}$} \\
\cline { 2 - 5 } & $\%[\mathrm{MgO}]$ & $\%\left[\mathrm{SiO}_{2}\right]$ & $\%[\mathrm{MgO}]$ & $\%\left[\mathrm{REO}_{3 / 2}\right]$ \\
\hline $2-27$ & 17.2 & $80.3 / 80.6$ & $17.1 / 16.9$ & $2.6 / 2.5$ \\
$28-65$ & 25.7 & $72.4 / 72.5$ & $25.3 / 25.0$ & $2.3 / 2.5$ \\
$66-125$ & 28.6 & $69.9 / 69.0$ & $27.9 / 28.2$ & $2.2 / 2.8$ \\
$126+$ & 31.0 & $68.6 / 66.9$ & $29.1 / 29.8$ & $2.3 / 3.3$ \\
\hline
\end{tabular}


Table 3.

\begin{tabular}{cccccc}
\hline \multirow{5}{*}{$\begin{array}{c}\text { NP size } \\
\text { (number of } \\
\text { Mg atoms) }\end{array}$} & $\mathrm{Q}^{0}$ & $\mathrm{Q}^{1}$ & $\mathrm{Q}^{2}$ & $\mathrm{Q}^{3}$ & $\mathrm{Q}^{4}$ \\
\cline { 2 - 6 } 0 & 0.00 & 0.00 & 0.00 & 0.01 & 99.99 \\
1 & 0.00 & 0.03 & 1.02 & 23.30 & 75.41 \\
$2-27$ & 0.05 & 0.28 & 3.25 & 31.86 & 64.42 \\
$28-65$ & 0.38 & 1.88 & 10.23 & 37.47 & 49.74 \\
$66-125$ & 0.67 & 3.73 & 12.59 & 38.97 & 43.96 \\
$126+$ & 1.05 & 5.51 & 14.17 & 37.51 & 41.60 \\
\hline
\end{tabular}


Table 4.

\begin{tabular}{c|c|ccccc|ccccc}
\hline \multirow{2}{*}{$\begin{array}{c}\text { NP size } \\
\text { (number of } \\
\text { Mg atoms) }\end{array}$} & \multirow{2}{*}{$\mathrm{r}(\AA)$} & \multicolumn{5}{|c|}{$\mathrm{N}_{\mathrm{Mg}-}$} & \multicolumn{5}{c}{ N-coordinated sites [\%] } \\
\cline { 3 - 11 } & & $\mathrm{O}$ & $\mathrm{NNO}$ & $\mathrm{NBO}^{*}$ & $\mathrm{NBO}^{* *}$ & BO* & 4 & 5 & 6 & 7 & 8 \\
\hline 1 & 1.92 & 5.59 & 0.00 & 1.89 & 0.01 & 3.69 & 8.81 & 37.77 & 37.18 & 14.48 & 1.17 \\
$2-27$ & 2.01 & 5.82 & 0.05 & 0.79 & 2.45 & 2.53 & 6.01 & 28.97 & 44.14 & 18.26 & 2.31 \\
$28-65$ & 2.03 & 6.12 & 0.17 & 0.40 & 3.56 & 1.99 & 4.32 & 17.71 & 43.20 & 30.89 & 3.89 \\
$66-125$ & 2.04 & 6.04 & 0.14 & 0.35 & 3.83 & 1.72 & 3.68 & 23.53 & 41.91 & 27.02 & 3.68 \\
$126+$ & 2.04 & 6.19 & 0.17 & 0.31 & 4.03 & 1.68 & 2.11 & 16.43 & 47.97 & 27.79 & 5.53 \\
\hline
\end{tabular}


Table 5.

\begin{tabular}{lccc}
\hline Glass composition & $1 \mathrm{RE}[\%]$ & $2 \mathrm{RE}[\%]$ & $3+\mathrm{RE}[\%]$ \\
\hline $0.01 \mathrm{EuO}_{3 / 2}-0.10 \mathrm{MgO}-0.89 \mathrm{SiO}_{2}$ & 65.3 & 23.2 & 11.5 \\
$0.01 \mathrm{EuO}_{3 / 2}-0.99 \mathrm{SiO}_{2}$ & 72.1 & 20.4 & 7.5 \\
\hline $0.01 \mathrm{ErO}_{3 / 2}-0.10 \mathrm{MgO}-0.89 \mathrm{SiO}_{2}$ & 64.0 & 21.7 & 14.3 \\
$0.01 \mathrm{ErO}_{3 / 2}-0.99 \mathrm{SiO}_{2}$ & 75.8 & 14.2 & 10.0 \\
\hline
\end{tabular}


Fig. 1.
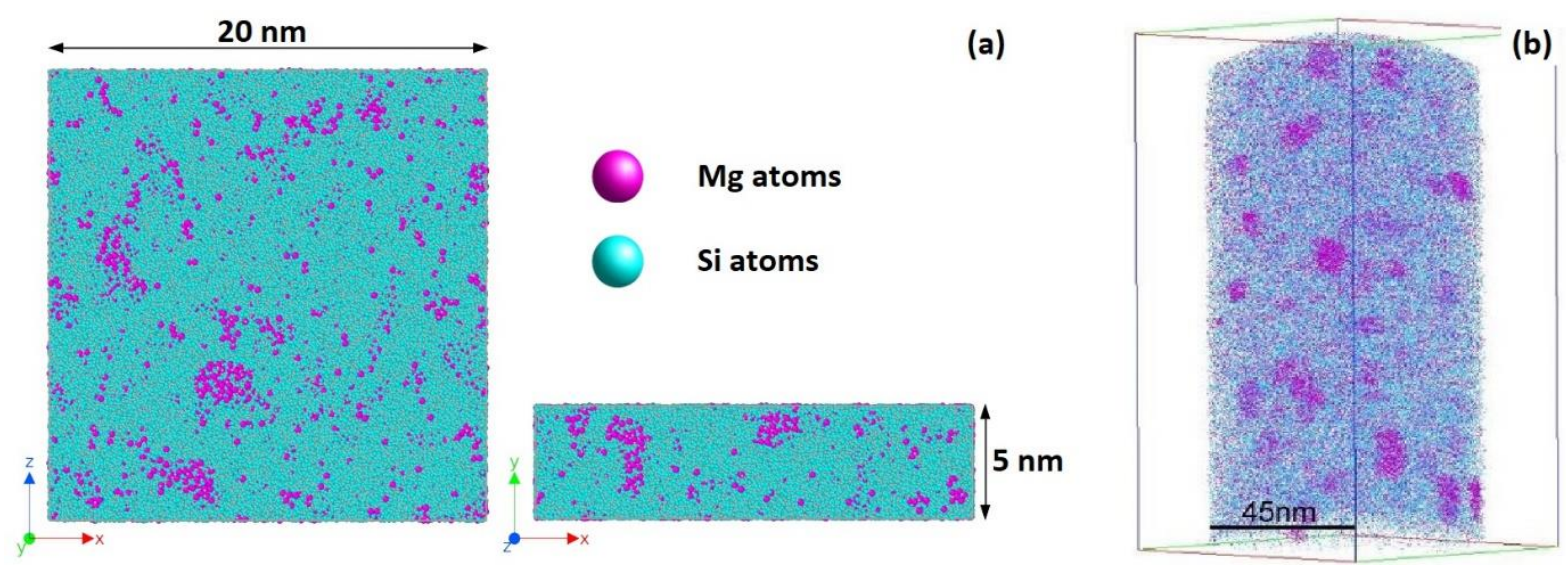
Fig. 2.

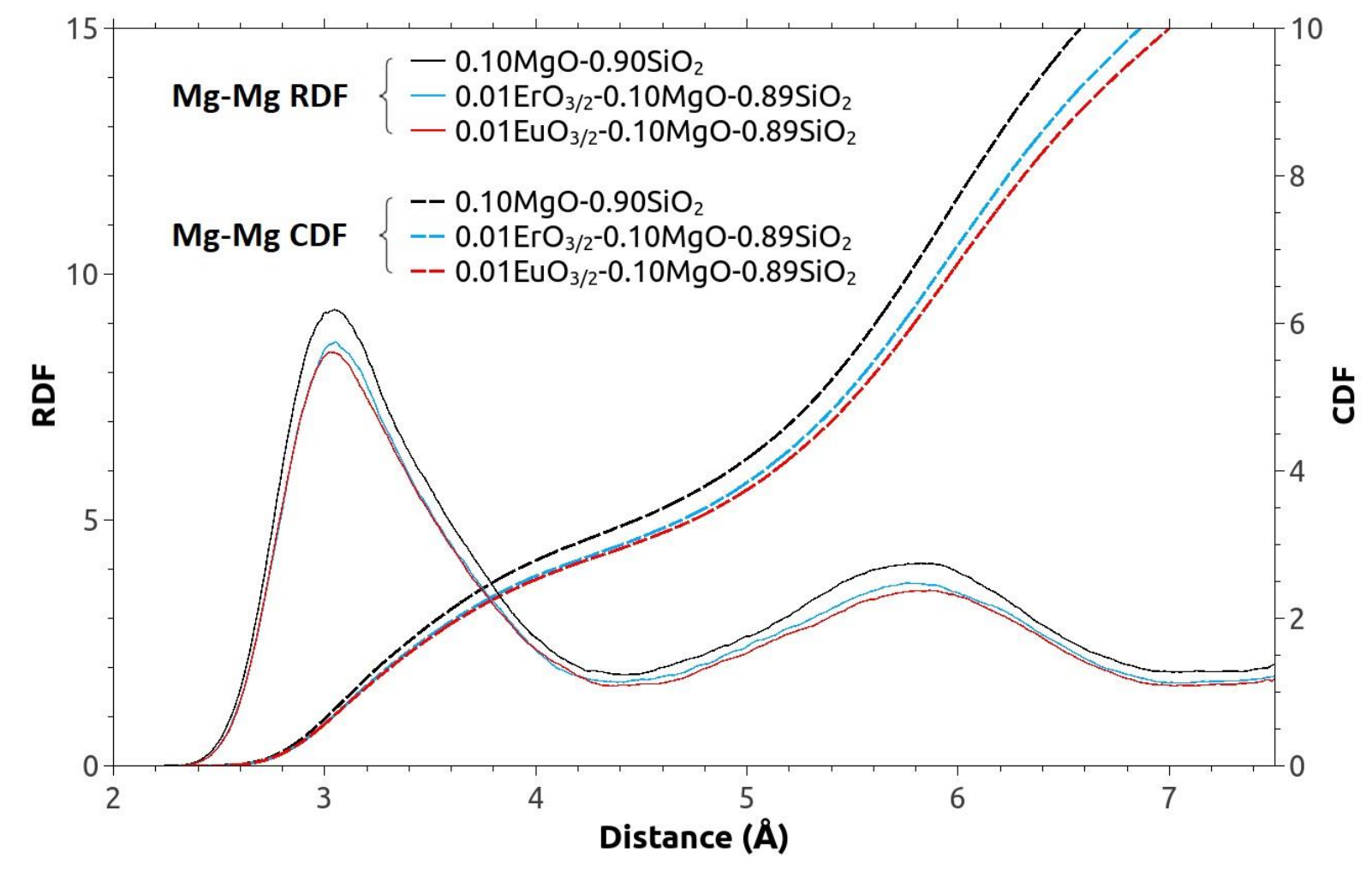


Fig. 3.
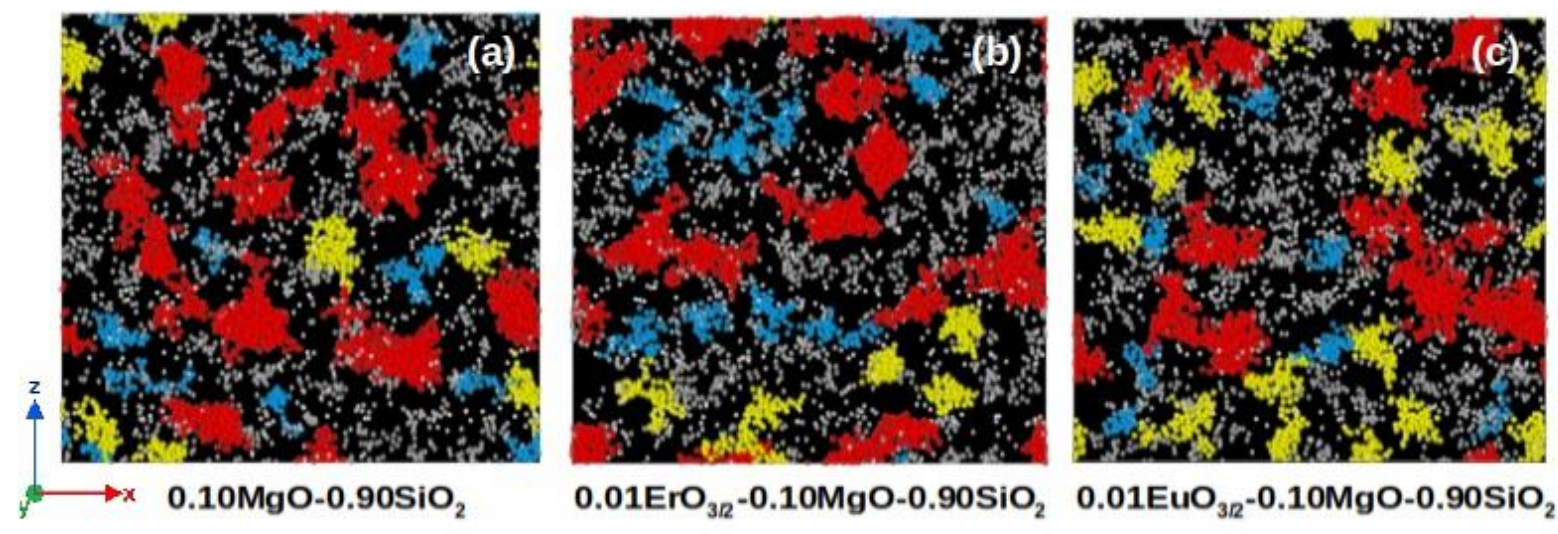

\begin{tabular}{|c|c|c|c|c|c|}
\hline NP color code & & & & \\
\hline $\begin{array}{c}\text { NP size } \\
\text { (number of Mg atoms) }\end{array}$ & 1 & $2-27$ & $28-65$ & $66-125$ & $126+$ \\
\hline
\end{tabular}


Fig. 4.

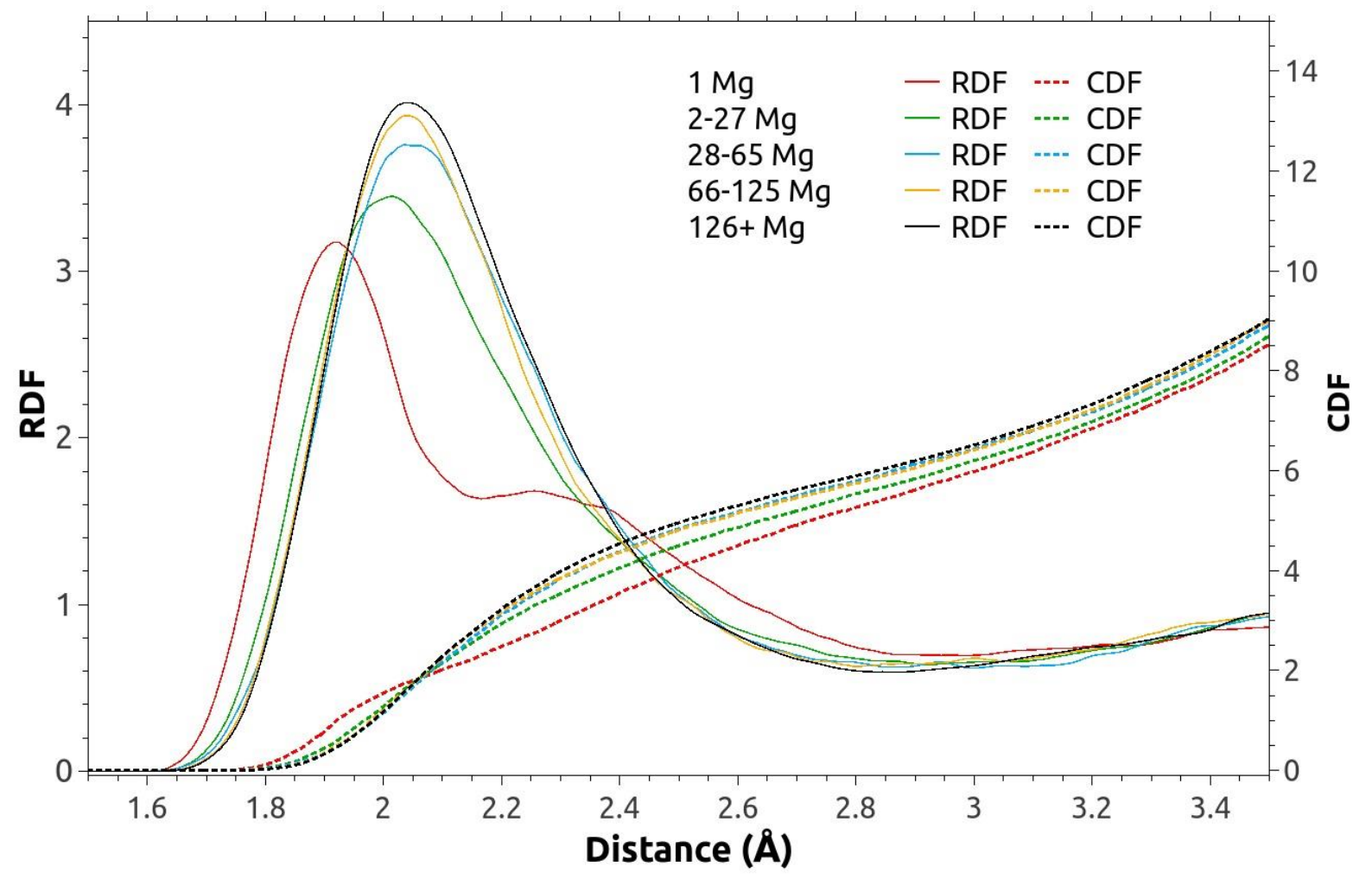


Fig. 5.
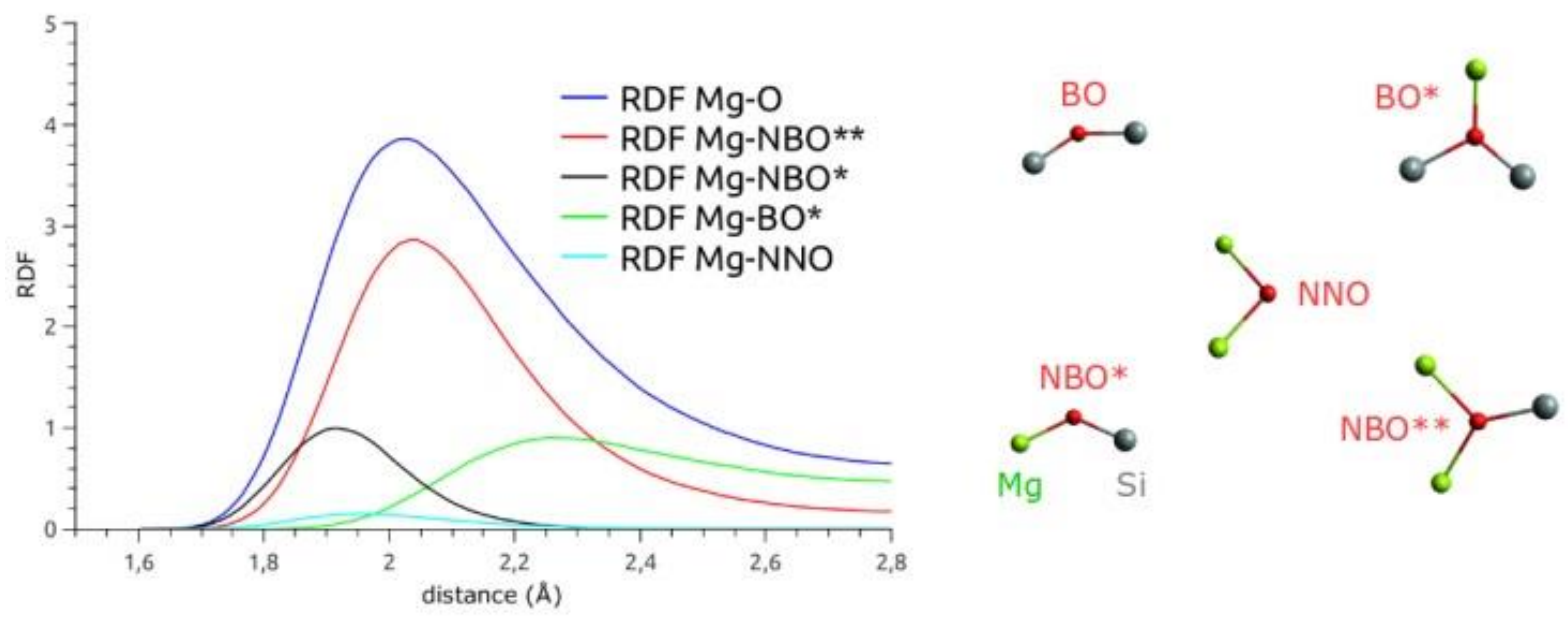
Fig. 6.

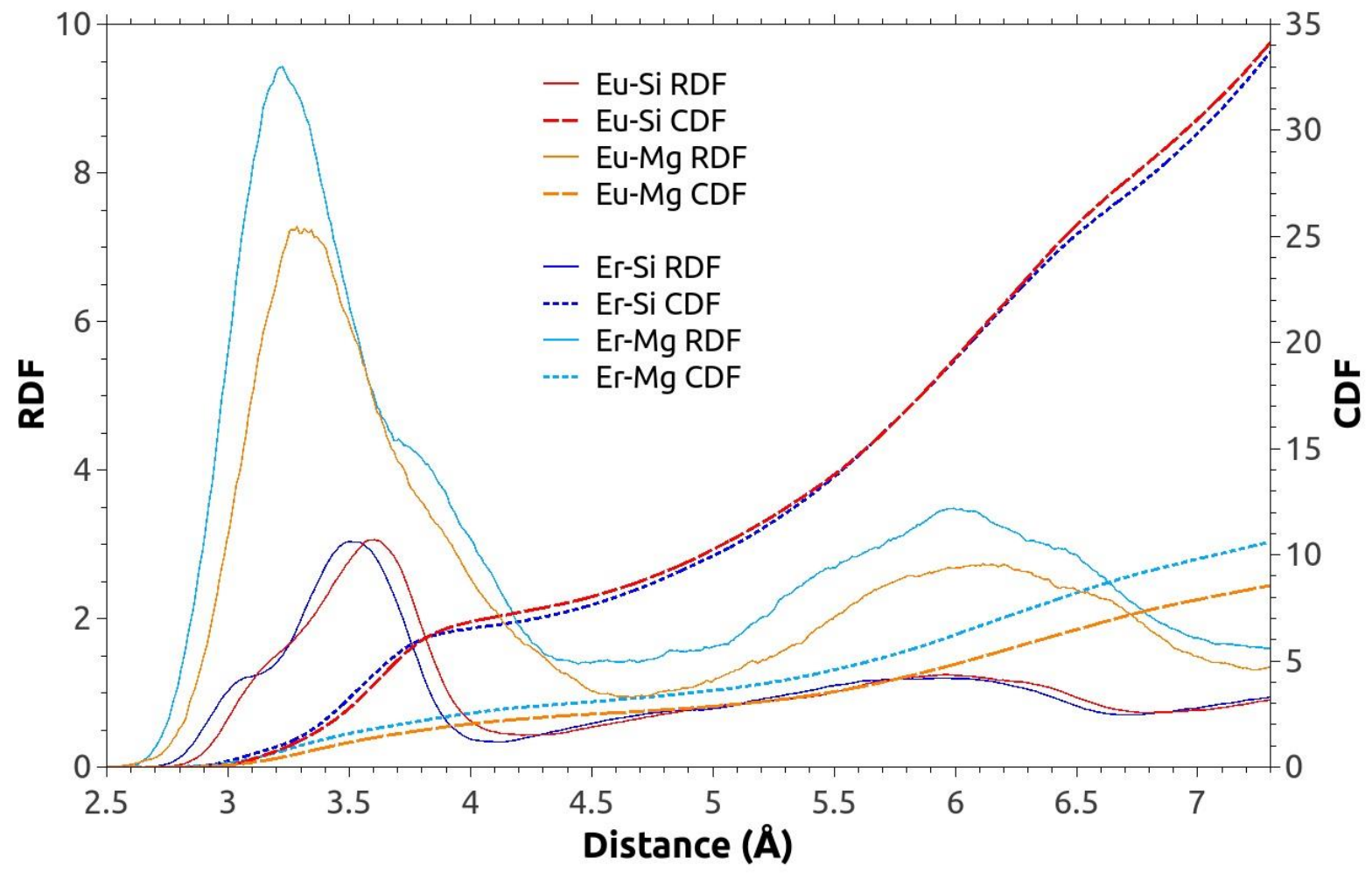


Fig. 7.

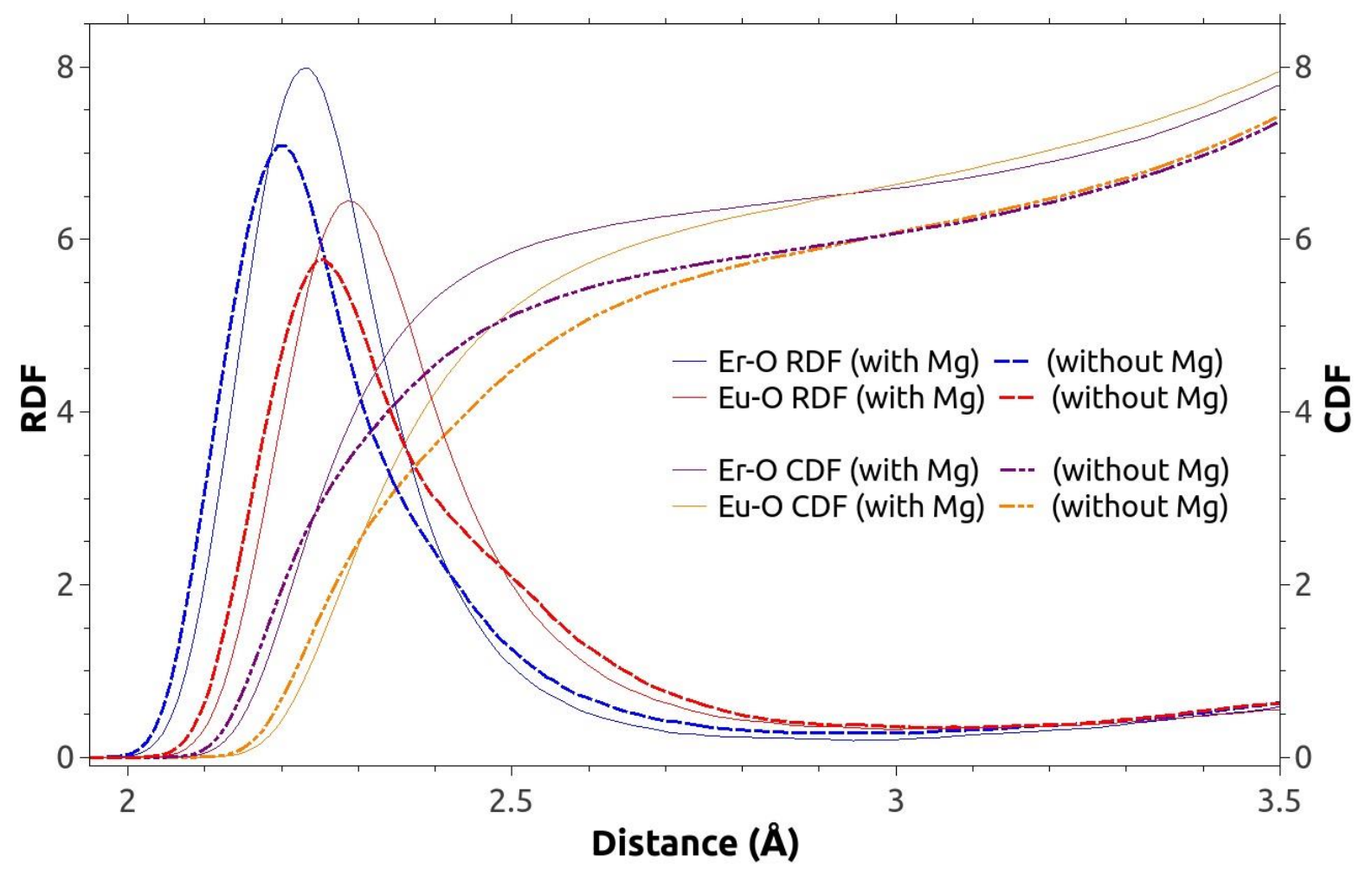


Fig. 8.
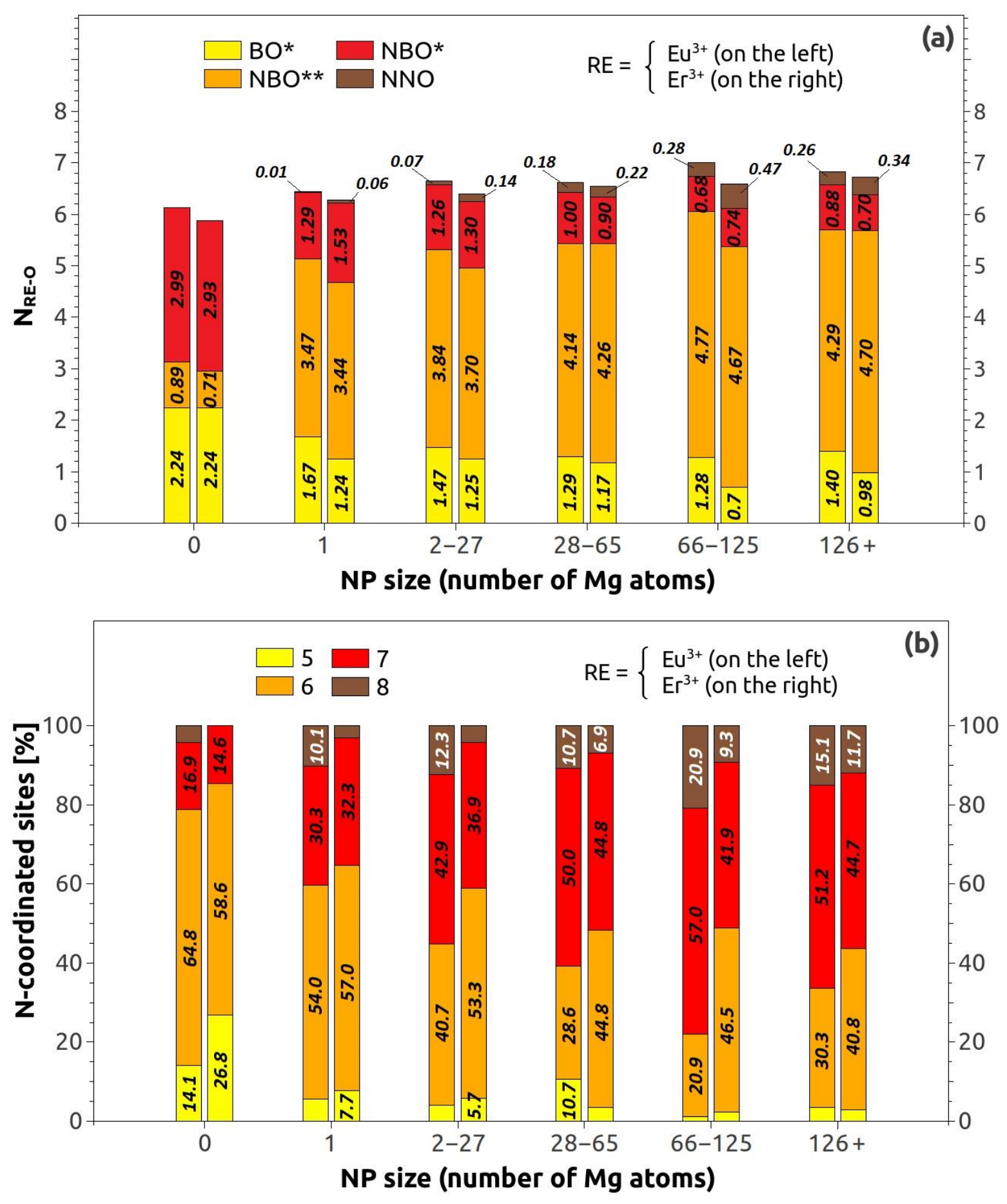
Fig. 9.
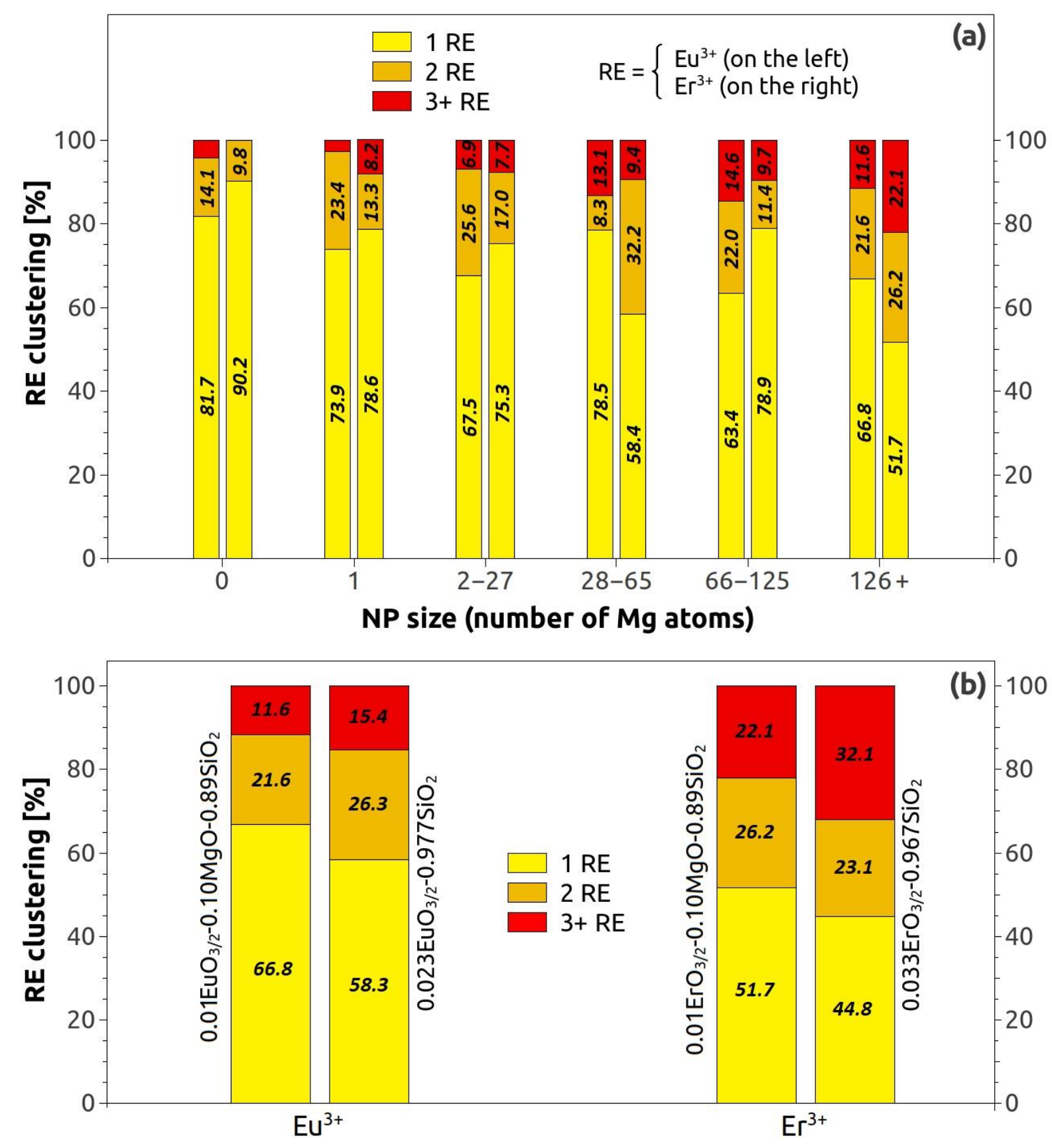
Fig. 10.
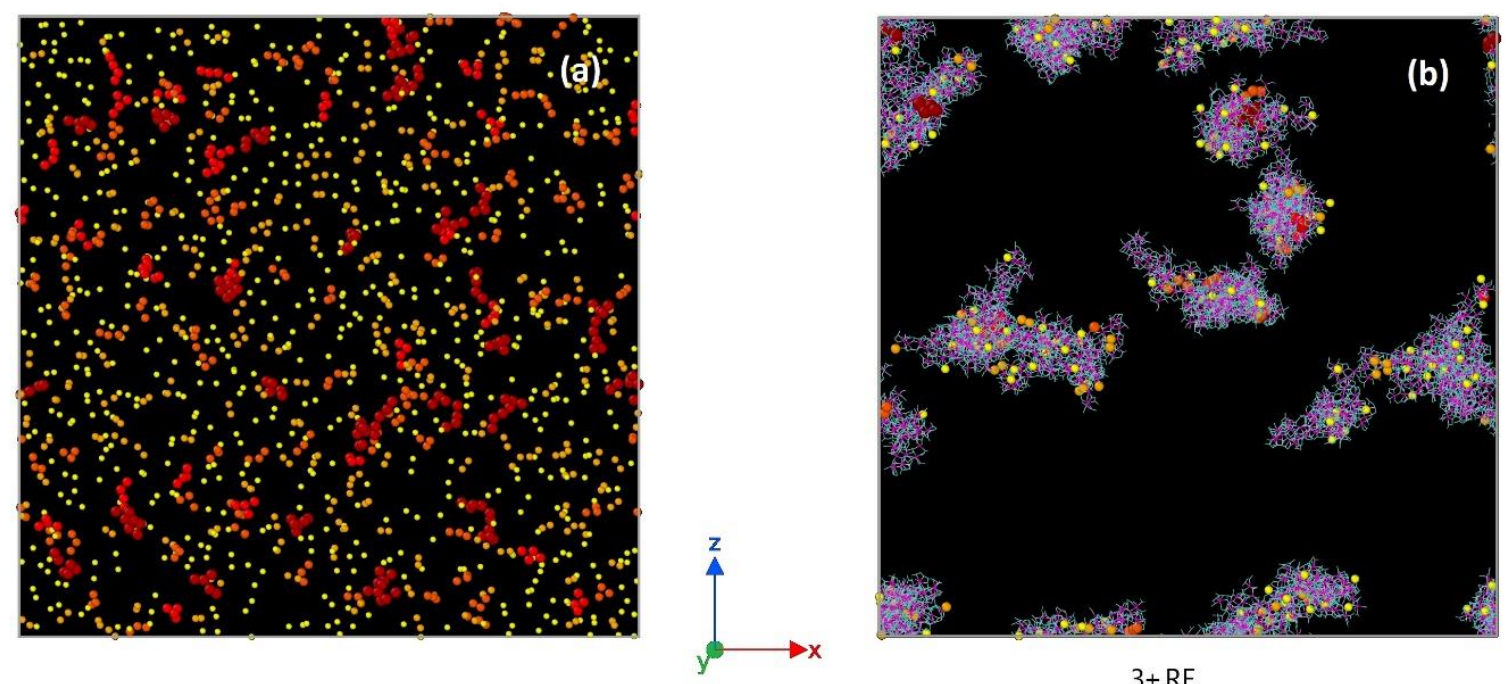

$3+R E$

RE degree of aggregation

(number of RE atoms)

$1 \mathrm{RE}$

$2 R E$

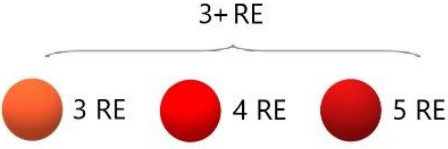

